\title{
Um estudo dos determinantes que precedem o núcleo dos movimentos prospectivos em textos opinativos
}

\section{A study of the determinants that precede the nucleus of the prospectives movements in the opinative texts}

\author{
Walleska Bernardino Silva - \\ Mestranda pelo Curso de Mestrado em Lingüística da \\ Universidade Federal de Uberlândia (UFU)
}

\section{RESUMO}

Este artigo objetiva demonstrar como se configuram os determinantes que precedem o núcleo dos movimentos prospectivos nos textos de opinião do jornal Folha de São Paulo. Para isso, analisamos trinta textos desse jornal, sendo quinze produções assinadas por Carlos Heitor Cony e as outras quinze por Clóvis Rossi.

Palavras-chave: movimentos prospectivos, determinantes; textos de opinião, referenciação.

\section{ABSTRACT}

The aim of this paper is to show how are configured the determinants that precede the nucleus of the prospectives movements in the opinative texts of the periodic newspaper "Folha de São Paulo". For that reason, we have analyzed thirty texts from that newspaper, being fifteen signed by Carlos Heitor Cony and the other fifteen by Clóvis Rossi.

Keywords: prospectives movements, determinants, opinative texts, reference.

\section{Introdução}

Assumindo que a linguagem verbal diferencia o homem de todos os outros animais e o singulariza nas relações sociais via construção de sentidos, nas várias esferas de comunicação, é que nos lançamos à proposta de estudar uma parte constitutiva dessa complexa rede comunicacional. O nosso objetivo, então, é analisar qual a maior recorrência de determinantes que precedem o núcleo dos movimentos prospectivos e sua implicação para os sintagmas que adiantam nos textos escritos a informação, ou seja, têm 
a capacidade de anunciá-la, chamando a atenção do leitor para elementos do texto que virão a posteriori.

Para observar tais determinantes, escolhemos trinta textos opinativos do jornal Folha de São Paulo, nos quais os movimentos prospectivos serão alvo de nossas análises a fim de verificarmos fatos referentes à organização e constituição do texto escrito, contribuindo para o desvelamento de elementos que atuam na composição dos textos na modalidade escrita da língua.

\section{Objetivo}

Analisaremos textos opinativos cujo domínio social da comunicação, segundo Dolz e Schneuwly (2004), remete à discussão de problemas sociais controversos e a capacidade de linguagem dominante diz respeito à sustentação, refutação e negociação de tomadas de posição. Nessa pesquisa, o nosso objetivo é verificar qual a maior recorrência de determinantes que precedem o núcleo dos movimentos prospectivos e sua conseqüência para os textos opinativos que, predominantemente, são argumentativos e que requerem, portanto, um uso adequado de lexias, bem como um arranjo sintático eficaz que garantam a comunicação almejada pelo produtor textual: elucidar o seu posicionamento sobre o tema debatido e mobilizar argumentos com a finalidade de conseguir a adesão do leitor ao seu ponto de vista.

\section{Abordagens teóricas}

Para iniciarmos nossas discussões é relevante ponderarmos de que lugar falamos, pois como dizia Saussure (1973, p.23) Bien loin que l'objet précède le point de vue, on dirait que c'est le point de vue qui crée l'objet. Escolhemos trabalhar os movimentos prospectivos sob perspectiva sociocognitivo-interacionista na qual os objetos-de-discurso são criados no decorrer do evento comunicativo (MONDADA e DUBOIS, 1995, p.21). Nessa perspectiva, a referência perde a sua ligação direta com o mundo para constituir-se num processo, a referenciação, em que a relação homem-mundo levará em conta aspectos como o contexto sócio-histórico-cognitivo que envolve os actantes na comunicação. 
A referenciação, então, abarcará os processos discursivos que permitirão, além do estabelecimento da coesão, percebida na linearidade do texto, 0 da coerência, responsável pela continuidade de sentidos ${ }^{1}$. Nesse trabalho, deter-nos-emos nas formas de introdução de referentes que viabilizam a tessitura do texto, caracterizada pela ligação estreita entre informação dada e informação nova.

Feitas as considerações do que entendemos sobre o processo que ativa e reativa referentes em nossa memória, passemos à explicitação do que concebemos como movimentos prospectivos. Comecemos a nossa exposição por uma ocorrência retirada do próprio corpus da pesquisa:

(A) É nisso que venho pensando cada vez mais: o mal do mundo não é a falta de razão, mas o excesso dela.

(CONY, C. H. Tudo passa. Folha de S. Paulo, São Paulo, 04 nov. 2006.)

Ao enunciar a proposição É nisso que venho pensando cada vez mais, Cony estabelece no leitor uma suspensão do sentido à medida que não introduz, em uma primeira instância, o objeto sobre o qual pensa cada vez mais, o que força o leitor a buscar pelo referente que satisfará à proposição, permitindo, dessa forma, a construção de sentido ao proferimento.

Nessa busca pelo sentido, o leitor é obrigado a lançar um "olhar à frente" para que o proferimento possa ser viabilizado por meio de uma complementação significativa que segue a prospecção. Ao esforço, então, de empreender a significação por meio de movimentos que demandam a projeção subseqüente ou posterior, chamamos de movimento prospectivo.

No caso da recorrência $(A)$, o que o jornalista pensa é que o mal do mundo não é a falta de razão, mas o excesso dela. Toda essa informação é reduzida ao pronome nisso que, de certa forma, condensa, toda a oração que o segue. Nesse sentido, nos reportamos ao que Francis (2003: 192) postula quanto à noção de rótulos, mais especificamente os prospectivos:

A principal característica do que será chamado de rótulo é que ele exige realização lexical, ou lexicalização, em seu cotexto: é um elemento nominal inerentemente não-específico cujo significado específico no discurso necessita ser precisamente decifrado ${ }^{2}$ (Winter, 1982,1992). Os rótulos podem funcionar tanto cataforicamente (para frente), quanto anaforicamente (para trás). Quando o rótulo preceder sua

\footnotetext{
${ }^{1}$ Conceito cunhado pelos teóricos Beaugrande e Dressler (1981, p.84) que diz respeito ao que eles concebem como coerência: continuidade de sentidos estabelecida ao longo dos textos.

${ }^{2}$ Grifo nosso.
} 
lexicalização, será chamado de rótulo prospectivo³; quando seguir sua lexicalização, será chamado de rótulo retrospectivo.

Assim, o pronome demonstrativo nisso configura-se como um termo inespecífico, isto é, sem um referente a priori do discurso, e que, ao condensar a informação subseqüente, exige lexicalização, transformação da informação em uma unidade lexical autônoma. Nesse sentido, podemos ainda pensar no pronome demonstrativo nisso como uma dêixis textual, cuja referência está contida no contexto de interlocução.

Dessa forma, evidenciados alguns de nossos posicionamentos teóricos frente ao que nos propusemos analisar, qual seria 0 interesse em perceber 0 movimento prospectivo, mais especificamente os determinantes precedentes do núcleo desse movimento em textos opinativos?

Partindo da idéia de que todo ato linguageiro reflete uma intenção comunicativa do locutor, esse pensamento nos direciona para a conclusão de que necessitamos indubitavelmente da interação para a projeção do ato comunicativo. Isso significa que durante o transcurso da enunciação, verbalizamos ou exteriorizamos nosso pensamento tendo em vista um interlocutor, mesmo que imaginário, conforme afirma Benveniste (1987, p.87): O que em geral caracteriza a enunciação é a acentuação da relação discursiva com o parceiro, seja este real ou imaginário, individual ou coletivo.

A linguagem verbalizada é, então, necessariamente permeada pela posição assumida pelo sujeito nos inúmeros contextos que o envolvem. Dessa forma, a idéia de que falar é externar a subjetividade na linguagem, torna-se adequada à língua em uso. Em outras palavras, o autor de uma produção verbal é necessariamente um agente social que se posiciona diante do mundo à medida que produz comunicação.

Com isso, os textos opinativos se estruturam lato sensu pela introdução de uma temática e por sua afirmação ou negação. Graças a esse mecanismo de negar ou afirmar é que se torna possível manipular a argumentatividade de modo a fazê-la parceira do ponto de vista do produtor. E, como representante explícito dessa indissociável subjetividade na linguagem, optamos por trabalhar os textos opinativos cujo nome já prevê a idéia de posicionamentos assumidos na produção textual que configura esse gênero.

No nosso enfoque, entendemos os textos opinativos como pertencentes ao agrupamento de gêneros da ordem do argumentar, segundo proposta de Dolz e Schneuwly (2004, p.43; 57) que consideram o agrupamento de gêneros como um instrumento para construir a progressão curricular. No agrupamento por nós considerado,

\footnotetext{
${ }^{3}$ Grifo nosso.
} 
tem-se como domínio social de comunicação a discussão de problemas sociais controversos e como capacidade de linguagem dominante a sustentação, refutação e negociação de tomadas de posição.

\section{Metodologia}

Para a realização da análise descritivo-analítica, foram selecionados trinta textos opinativos da seção Opinião do jornal Folha de São Paulo. A seleção constou de quinze textos do articulista Carlos Heitor Cony e quinze de Clóvis Rossi. A captação dos textos obedeceu ao seguinte critério: foram recolhidos os cinco primeiros textos dos articulistas supracitados no período compreendido pelos meses: outubro, novembro e dezembro do ano de 2006.

Após a escolha do material para a pesquisa, iniciamos a identificação dos movimentos prospectivos e, em seguida, passamos a identificar os determinantes que precedem o núcleo dos movimentos prospectivos para, então, proceder às análises textual e discursiva dos dados encontrados.

\section{Identificação dos movimentos prospectivos no corpus}

Movimentos prospectivos presentes nos textos opinativos de Carlos Heitor Cony

\begin{tabular}{|l|l|c|l|}
\hline $\begin{array}{c}\text { Data de } \\
\text { publica- } \\
\text { ção do } \\
\text { texto }\end{array}$ & $\begin{array}{l}\text { Título do } \\
\text { texto }\end{array}$ & $\begin{array}{c}\text { Número } \\
\text { da ocorrência }\end{array}$ & \multicolumn{1}{|c|}{ Ocorrências } \\
\hline $03 / 10 / 06$ & $\begin{array}{l}\text { "Tempora } \\
\text { da de } \\
\text { palpites" }\end{array}$ & 1 & $\begin{array}{l}\text { "Pensando bem, e com exceção de casos } \\
\text { isolados nos diversos níveis das eleições } \\
\text { de domingo, os resultados eram mais ou } \\
\text { menos esperados: sobretudo a queda de } \\
\text { Lula e a surpreendente arrancada final de } \\
\text { Alckmin." }\end{array}$ \\
\hline $04 / 10 / 06$ & $\begin{array}{l}\text { "A turma } \\
\text { dos } \\
\text { exóticos" }\end{array}$ & $\begin{array}{l}\text { "Esta é a finalidade básica das punições } \\
\text { a qualquer crime: a integração na } \\
\text { sociedade." }\end{array}$ \\
\hline $05 / 10 / 06$ & $\begin{array}{l}\text { seguranç de } \\
\text { a" }\end{array}$ & 3 & $\begin{array}{l}\text { "De igual forma, todo o nosso equipamento } \\
\text { vital é precário diante daquilo que deu } \\
\text { título a uma ópera de Verdi: a força do } \\
\text { destino". }\end{array}$ \\
\hline $02 / 11 / 06$ & "Sopa de & 4 & \begin{tabular}{l} 
"Mas a opinião pública é como aquela \\
\hline
\end{tabular}
\end{tabular}




\begin{tabular}{|c|c|c|c|}
\hline & entulho" & & dona da ópera de Verdi: "è mobile"." \\
\hline $04 / 11 / 06$ & $\begin{array}{l}\text { "Tudo } \\
\text { passa" }\end{array}$ & 5 & $\begin{array}{l}\text { "Um curador de menores, aqui no Rio, } \\
\text { garantiu que as revistas e filmes eróticos } \\
\text { tinham nascido de uma resolução tomada } \\
\text { em Havana, em 1968, e faziam parte de } \\
\text { uma estratégia para os comunistas } \\
\text { chegarem ao poder. Essa besteira teve } \\
\text { equivalente à } \emptyset \text { [coligação]esquerda: } \\
\text { ouvi de um comunista histórico a afirmação } \\
\text { de que a pornografia e a droga eram } \\
\text { agenciadas pela CIA com a finalidade de } \\
\text { enfraquecer o ímpeto libertário dos povos } \\
\text { do Terceiro Mundo." }\end{array}$ \\
\hline $04 / 11 / 06$ & $\begin{array}{l}\text { "Tudo } \\
\text { passa" }\end{array}$ & 6 & $\begin{array}{l}\text { "É nisso que venho pensando cada vez } \\
\text { mais: o mal do mundo não é a falta de } \\
\text { razão, mas o excesso dela." }\end{array}$ \\
\hline $06 / 11 / 06$ & $\begin{array}{l}\text { "Um } \\
\text { conselho } \\
\text { ao papa" }\end{array}$ & 7 & $\begin{array}{l}\text { "Dele tenho poucas certezas: é fiel ao } \\
\text { patrão, fiel até mesmo aos amigos do } \\
\text { patrão." }\end{array}$ \\
\hline $06 / 11 / 06$ & $\begin{array}{l}\text { "Um } \\
\text { conselho } \\
\text { ao papa" }\end{array}$ & 8 & $\begin{array}{l}\text { "Lê jornais alternativos da Baixada } \\
\text { Fluminense e sabe de coisas que os } \\
\text { outros jornais nem ousam suspeitar. Casos } \\
\text { de adultério que terminam em facadas, } \\
\text { roubo de crianças para revenda na } \\
\text { Alemanha, bandos inteiros massacrados } \\
\text { por policiais do Esquadrão da Morte -fala } \\
\text { pouco, mas sabe muito e eventualmente } \\
\text { avisa que um dia vai embora, não sabe } \\
\text { ainda para onde." }\end{array}$ \\
\hline $06 / 11 / 06$ & $\begin{array}{l}\text { "Um } \\
\text { conselho } \\
\text { ao papa" }\end{array}$ & 9 & $\begin{array}{l}\text { "Ouviu meus argumentos com seriedade, } \\
\text { mas encerrou o diálogo com uma } \\
\text { advertência que transmito à Sua } \\
\text { Santidade: "Eu, se fosse o papa, não } \\
\text { colocaria os pés aqui"." }\end{array}$ \\
\hline $03 / 12 / 06$ & $\begin{array}{l}\text { "Um } \\
\text { gesto de } \\
\text { paz" }\end{array}$ & 10 & $\begin{array}{l}\text { "Também para os muçulmanos ele lembrou } \\
\text { que as diferenças das duas religiões não } \\
\text { afetam o princípio básico de cada uma, } \\
\text { que é a crença num só Deus." }\end{array}$ \\
\hline $03 / 12 / 06$ & $\begin{array}{l}\text { "Um } \\
\text { gesto de } \\
\text { paz" }\end{array}$ & 11 & $\begin{array}{l}\text { "Do ponto de vista estritamente religioso, a } \\
\text { visita de Bento } 16 \text { segue a linha } \\
\text { apostólica de São Paulo: não adianta } \\
\text { converter os convertidos." }\end{array}$ \\
\hline $05 / 12 / 06$ & $\begin{array}{l}\text { "Jece } \\
\text { Valadão" }\end{array}$ & 12 & $\begin{array}{l}\text { "Como John Wayne ou Jean Gabin, ele se } \\
\text { fixaria num tipo: o do brasileiro gingado, } \\
\text { com muitos macetes e nenhum caráter." }\end{array}$ \\
\hline $05 / 12 / 06$ & $\begin{array}{l}\text { “Jece } \\
\text { Valadão" }\end{array}$ & 13 & $\begin{array}{l}\text { "A frente das câmeras, contudo, surge a } \\
\text { imagem mais constante de nosso } \\
\text { cinema. Wilson Grey, único ator que } \\
\text { apareceu em mais filmes do que ele, foi } \\
\text { coadjuvante." }\end{array}$ \\
\hline
\end{tabular}

Dos 15 textos pesquisados, 7 não apresentaram ocorrência de movimentos prospectivos. Por ordem de publicação, foram os textos: "Mais problemas do que votos" (01/10/06); "Objetivo nacional" 
(02/10/06); "O homem da imprensa" (01/11/06); “ “Um Filme É para Sempre”” (05/11/06); "Anatomia do vigarista” (02/12/06);“Gastos e ganhos” (04/12/06) e "Tempos modernos” (06/12/06).

\section{Movimentos prospectivos presentes nos textos opinativos de Clóvis Rossi}

\begin{tabular}{|c|c|c|c|}
\hline $\begin{array}{c}\text { Data de } \\
\text { publicação } \\
\text { do texto }\end{array}$ & $\begin{array}{l}\text { Título do } \\
\text { texto }\end{array}$ & $\begin{array}{l}\text { Número } \\
\text { da } \\
\text { ocorrência }\end{array}$ & Ocorrências \\
\hline $01 / 10 / 06$ & $\begin{array}{l}\text { "Tiros } \\
\text { ética" }\end{array}$ & 14 & $\begin{array}{l}\text { "A campanha eleitoral } 2006 \text { termina como } \\
\text { começou a } \varnothing \text { [campanha] de 2002: com } \\
\text { fotos de pilhas e pilhas de dinheiro, feitas } \\
\text { pela Polícia Federal ao apreendê-las das } \\
\text { mãos de operadores políticos (para usar } \\
\text { um eufemismo bem brando que é } \\
\text { domingo, dia do Senhor)." }\end{array}$ \\
\hline $01 / 10 / 06$ & $\begin{array}{l}\text { "Tiros } \\
\text { ética" }\end{array}$ & 15 & $\begin{array}{l}\text { "São dois instantâneos preciosos do } \\
\text { modo de fazer política no Brasil. } \\
\text { Primeiro, porque revelam que políticos de } \\
\text { diferentes partidos operam com dinheiro } \\
\text { cuja origem não pode ser bem explicada. } \\
\text { Já é eloqüente. Mas, no caso do PT, Ø [a } \\
\text { situação] é pior: se a origem é obscura e } \\
\text { portanto suspeita, a finalidade é ainda } \\
\text { mais sórdida, como o próprio presidente } \\
\text { da República já admitiu uma e outra vez." }\end{array}$ \\
\hline 01/10/06 & $\begin{array}{l}\text { "Tiros } \\
\text { ética" }\end{array}$ & 16 & $\begin{array}{l}\text { "Mas há um segundo dado, igualmente } \\
\text { sórdido: a tentativa, em ambos os casos, } \\
\text { de atacar a divulgação da foto, em vez de } \\
\text { explicar o dinheiro." }\end{array}$ \\
\hline $03 / 10 / 06$ & $\begin{array}{l}\text { "O mito do } \\
\text { mito" }\end{array}$ & 17 & $\begin{array}{l}\text { "Por ironia, Fernando Henrique Cardoso, } \\
\text { com quem os petistas adoram fazer } \\
\text { comparações, se saiu melhor que Lula } \\
\text { quando Ihe tocou participar do referendo } \\
\text { reeleitoral em 1998: ganhou no primeiro } \\
\text { turno, com } 53 \% \text { dos votos válidos, contra } \\
48,6 \% \text { de Lula agora. No entanto, nem } \\
\text { FHC, vaidoso assumido, se acha um } \\
\text { herói popular. } \\
\text { Tem Ø [algo] mais: Lula não conseguiu } \\
\text { vencer no primeiro turno mesmo } \\
\text { enfrentando um candidato virgem em } \\
\text { disputas nacionais e com assumido sabor } \\
\text { de picolé de chuchu, ao contrário de FHC, } \\
\text { que derrotou o já muito rodado e mais } \\
\text { carismático Luiz Inácio Lula da Silva." }\end{array}$ \\
\hline $03 / 10 / 06$ & $\begin{array}{l}\text { "O mito do } \\
\text { mito" }\end{array}$ & 18 & $\begin{array}{l}\text { "Conclusão inescapável: não há quem } \\
\text { encarne um projeto capaz de formar uma } \\
\text { maioria própria." }\end{array}$ \\
\hline $04 / 10 / 06$ & "Candidatos & 19 & "Uma frase, duas revelações, ainda que \\
\hline
\end{tabular}




\begin{tabular}{|c|c|c|c|}
\hline & de plástico" & & $\begin{array}{l}\text { uma desnecessária. Primeira revelação } \\
\text { (conhecida): os ricos é que realmente } \\
\text { ganharam dinheiro em seu governo. } \\
\text { Logo, a imagem de "pai dos pobres" é } \\
\text { pura demagogia. } \\
\text { Os números dão razão a Lula: } \mathrm{R} \$ 110 \\
\text { bilhões para remunerar os detentores dos } \\
\text { títulos da dívida pública (todos ricos, } \\
\text { alguns podres de ricos) e apenas R } \$ 7 \\
\text { bilhões para o Bolsa Família, destinados } \\
\text { aos pobres entre os pobres. A segunda } \\
\text { revelação é o incontido desejo, típico em } \\
\text { novo rico, de ser querido e amado pelos } \\
\text { "velhos ricos"." }\end{array}$ \\
\hline $06 / 10 / 06$ & $\begin{array}{l}\text { "A rota que } \\
\text { está ausente" }\end{array}$ & 20 & $\begin{array}{l}\text { "Mas me atrevo a puxar o que me } \\
\text { pareceu o mote principal: "A economia } \\
\text { brasileira só irá bem quando voltar a } \\
\text { crescer } 7 \% \text { ao ano"." }\end{array}$ \\
\hline 03/11/06 & $\begin{array}{l}\text { "Cenas } \\
\text { patéticas" }\end{array}$ & 21 & $\begin{array}{l}\text { "Patética é a desculpa que setores da } \\
\text { esquerda deram para votar nele de novo: } \\
\text { seria a maneira de forçar uma guinada à } \\
\text { esquerda no segundo mandato." }\end{array}$ \\
\hline $04 / 11 / 06$ & $\begin{array}{l}\text { "O Carandiru } \\
\text { aéreo" }\end{array}$ & 22 & $\begin{array}{l}\text { "É preciso uma defensora do consumidor } \\
\text { como Maria Inês Dolci, na Folha de } \\
\text { ontem, para apontar o dedo para o } \\
\text { verdadeiro culpado: "O desvio das } \\
\text { verbas para segurança aérea, a partir de } \\
\text { 2003, já sob o domínio do "nunca } \\
\text { ninquém jamais"." }\end{array}$ \\
\hline $10 / 12 / 06$ & $\begin{array}{l}\text { "De filósofos e } \\
\text { de } \\
\text { profissionais" }\end{array}$ & 23 & $\begin{array}{l}\text { Innerarity começa por descrever a } \\
\text { política de uma maneira que dá a } \\
\text { sensação de que ele acompanhou de } \\
\text { perto as recentes eleições no Brasil: } \\
\text { "Boa parte do mal-estar que gera a } \\
\text { política se deve precisamente à } \\
\text { impressão que oferece de ser uma } \\
\text { atividade pouco inteligente, de curto } \\
\text { alcance, mera tática oportunista, repetitiva } \\
\text { até o fastio, rígida em seus esquema } \\
\text { convencionais e que só se corrige por } \\
\text { cálculo de conveniência", escreve. } \\
\text { Depois, ergue o brado "contra os } \\
\text { administradores oficiais do realismo", } \\
\text { para "defender que a política não é mera } \\
\text { administração nem mera adaptação, mas } \\
\text { configuração, desenho dos marcos de } \\
\text { atuação, adivinhação do futuro". } \\
\text { Continua: "Tem a ver com o inédito e o } \\
\text { insólito, magnitudes que não comparecem } \\
\text { em outras profissões muito honradas, } \\
\text { mas alheias às inquietudes que provoca o } \\
\text { excesso incerteza". } \\
\text { de }\end{array}$ \\
\hline
\end{tabular}




\begin{tabular}{|c|c|c|c|}
\hline & & & $\begin{array}{l}\text { Termina dizendo que "quem for capaz de } \\
\text { conceber essa incerteza como } \\
\text { oportunidade verá que a erosão de } \\
\text { alguns conceitos tradicionais torna } \\
\text { novamente possível a política como força } \\
\text { de inovação e transformação". }\end{array}$ \\
\hline $12 / 12 / 06$ & $\begin{array}{l}\text { "Sobre } \\
\text { Pinochet e a } \\
\text { Plaza Itália" }\end{array}$ & 24 & $\begin{array}{l}\text { "(...) fiz a carreira ao contrário do usual: } \\
\text { comecei chefe, morrerei repórter (...)" }\end{array}$ \\
\hline $12 / 12 / 06$ & $\begin{array}{l}\text { "Sobre } \\
\text { Pinochet e a } \\
\text { Plaza Itália" }\end{array}$ & 25 & $\begin{array}{l}\text { "Microcenas que me marcaram para a } \\
\text { vida: sangue nas águas do Mapocho, o } \\
\text { riozinho que banha a capital chilena, } \\
\text { produto de cadáveres que ali caíram (ou } \\
\text { foram jogados); aquela famosa cena da } \\
\text { queima de livros, coisa que parecia saída } \\
\text { de velhos filmes do nazismo; o desespero } \\
\text { de pais e mães às portas do Estádio } \\
\text { Nacional, transformado em mega-prisão." }\end{array}$ \\
\hline $12 / 12 / 06$ & $\begin{array}{l}\text { "Sobre } \\
\text { Pinochet e a } \\
\text { Plaza Itália" }\end{array}$ & 26 & $\begin{array}{l}\text { "Ao longe, o som de metralhadoras nas } \\
\text { "poblaciones"; na cabeça, o refrão de } \\
\text { uma canção do Inti-Ilimani: "Están } \\
\text { matando chilenos, ay que haremos/ay } \\
\text { que haremos?". }\end{array}$ \\
\hline $14 / 12 / 06$ & $\begin{array}{l}\text { "Falta a sua } \\
\text { pressão" }\end{array}$ & 27 & $\begin{array}{l}\text { "Manchete do caderno Dinheiro desta } \\
\text { Folha no domingo: "Renda da classe } \\
\text { média cai } 46 \% \text { em } 6 \text { anos"." }\end{array}$ \\
\hline $14 / 12 / 06$ & $\begin{array}{l}\text { "Falta a sua } \\
\text { pressão" }\end{array}$ & 28 & $\begin{array}{l}\text { "Comentário de Sílvio Meira para } \\
\text { recente número da revista "Surcos", } \\
\text { publicação chilena } \\
\text { desenvolvimento: "A história demonstra } \\
\text { que é muito difícil que prospere um país } \\
\text { que não tenha uma classe média } \\
\text { estruturada econômica, social, cultural e } \\
\text { politicamente. E a história demonstra que } \\
\text { quem cria emprego em todas as áreas da } \\
\text { economia do país é a classe média"." }\end{array}$ \\
\hline $20 / 12 / 06$ & $\begin{array}{l}\text { "Resta } \\
\text { escracho" }\end{array}$ & 29 & $\begin{array}{l}\text { "Aliás, é bom imitar, com adendos, Janio } \\
\text { de Freitas e dar nome às exceções: } \\
\text { Fernando Gabeira e Chico Alencar (RJ); } \\
\text { Mendes Thame, Luiza Erundina e Carlos } \\
\text { Sampaio (SP); Raul Jungmann e Roberto } \\
\text { Freire (PE); Walter Pinheiro (BA); Renato } \\
\text { Casagrande (ES); Henrique Fontana e } \\
\text { Luciana Genro (RS). E os senadores } \\
\text { Eduardo Suplicy, Jefferson Péres, Heloísa } \\
\text { Helena e Cristovam Buarque." }\end{array}$ \\
\hline
\end{tabular}

Dos 15 textos pesquisados, 5 não apresentaram ocorrência de movimentos prospectivos. Por ordem de publicação, foram os textos: “A origem dos 'bandidos"” ((05/10/06); “Lula e as gripes” (01/11/06); "O grito e o pacto" (02/11/06); "O espelho e a indigência mental" (05/11/06) e "Um Nobel para Lula" $(13 / 12 / 06)$. 
6. Tabela referente aos determinantes encontrados juntamente com o núcleo dos movimentos prospectivos

\begin{tabular}{|c|c|c|}
\hline $\begin{array}{c}\text { Número } \\
\text { das } \\
\text { ocorrências }\end{array}$ & $\begin{array}{l}\text { Determinantes } \\
\text { que precedem o } \\
\text { núcleo dos } \\
\text { movimentos } \\
\text { prospectivos }\end{array}$ & $\begin{array}{l}\text { Morfologia dos } \\
\text { determinantes }\end{array}$ \\
\hline 1 & Os & Artigo definido \\
\hline 2 & $A$ & Artigo definido \\
\hline 3 & $x$ & $x$ \\
\hline 4 & Aquela & $\begin{array}{c}\text { Pronome } \\
\text { demonstrativo }\end{array}$ \\
\hline 5 & $A$ & Artigo definido \\
\hline 6 & $x$ & $x$ \\
\hline 7 & Poucas & $\begin{array}{l}\text { Pronome } \\
\text { indefinido }\end{array}$ \\
\hline 8 & $x$ & $x$ \\
\hline 9 & Uma & Numeral \\
\hline 10 & 0 & Artigo definido \\
\hline 11 & A & Artigo definido \\
\hline 12 & $\mathrm{Um}$ & Artigo indefinido \\
\hline 13 & A & Artigo definido \\
\hline 14 & A & Artigo definido \\
\hline 15 & $\varnothing$ & $\varnothing$ \\
\hline 16 & Um & Artigo indefinido \\
\hline 17 & $\varnothing$ & $\varnothing$ \\
\hline 18 & $x$ & $x$ \\
\hline 19 & Duas & Numeral \\
\hline 20 & $\mathrm{O}$ & Artigo definido \\
\hline 21 & A & Artigo definido \\
\hline 22 & $\mathrm{O}$ & Artigo definido \\
\hline 23 & $x$ & $x$ \\
\hline 24 & A & Artigo definido \\
\hline 25 & $x$ & $x$ \\
\hline 26 & $\mathrm{O}$ & Artigo definido \\
\hline 27 & $x$ & $x$ \\
\hline 28 & $x$ & $x$ \\
\hline 29 & As & Artigo definido \\
\hline
\end{tabular}




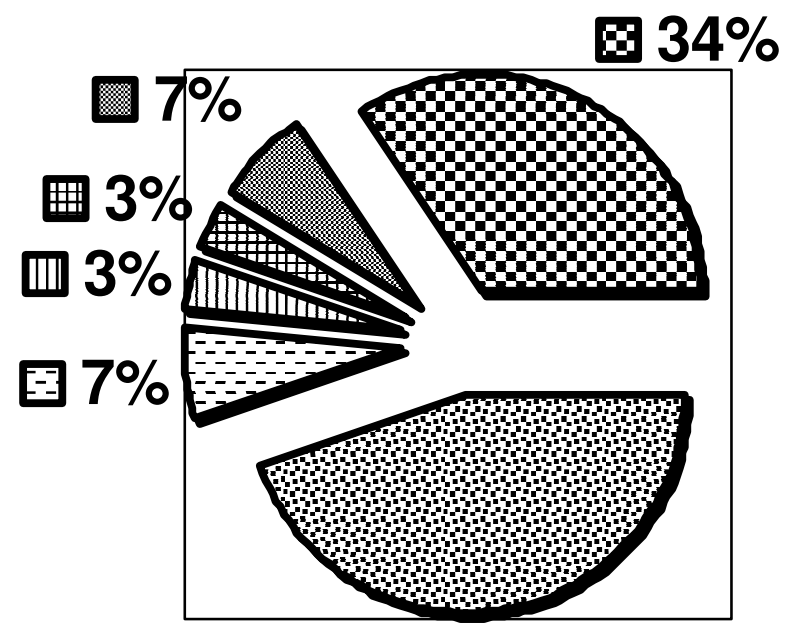

圈 46\%
용 Artigo Definido

Q Artigo Indefinido

四 Pronome Demonstrativo

囲 Pronome Indefinido

Numeral

Q Nenhum

Determinante

\section{Discussão dos resultados}

Pudemos constatar ao longo de nossa pesquisa que o índice de aparecimento do determinante precedente ao núcleo do movimento prospectivo enquanto artigo definido foi superior se comparado com o restante das ocorrências. Tentaremos traçar algumas discussões a partir desse levantamento.

De acordo com Cunha e Cintra (2001, p. 205),

Dá se o nome de artigos às palavras o (com variações a, os, as) e um (com as variações uma, uns, umas), que se antepõem aos substantivos para indicar: a) que se trata de um ser já conhecido do leitor ou do ouvinte, seja por ter sido mencionado antes, seja por ser objeto de um conhecimento de experiência (...) b) que se trata de um simples representante de uma dada espécie ao qual não se fez menção anterior. (...) No primeiro caso, dizemos que o artigo é definido; no segundo, indefinido.

O intuito dessa citação é justamente promover reflexões que embasam o uso do artigo definido no nosso corpus. De início, como afirmaram Cunha e Cintra (2001, p.205), o definido indica que se trata de um ser já conhecido do leitor ou do ouvinte, seja por ter sido mencionado antes, seja por ser objeto de um conhecimento de experiência (...). Nesse momento, é preciso analisarmos o porquê da ocorrência maior de artigos definidos precedendo o núcleo dos movimentos prospectivos, haja vista que nesse tipo de movimento o sentido é suspenso, até que se lance um "olhar à frente" em sua busca. Em 
outras palavras, não há como tratar-se de um ser já conhecido do leitor ou do ouvinte, como propõe a gramática, seja por ser objeto de conhecimento da experiência ou muito menos por ser anteriormente mencionado. Se assim o fosse, não se teria a necessidade de empreender esforço subseqüente para produção de sentidos.

Dessa forma, o uso do definido aqui contraria as expectativas do que propõe a gramática normativa, haja vista que o locutor ainda enunciará a informação e, serve-se, para isso, do mecanismo que adianta nos textos escritos essa informação, ou seja, tem a capacidade de anunciá-la.

Esperávamos, como se trata de movimentos prospectivos, que se utilizassem com maior freqüência artigos indefinidos antecedendo o núcleo desses movimentos, como nas ocorrências 12 e 16 do corpus, posto que a informação será dada a posteriori.

Ocorrência 12: "Como John Wayne ou Jean Gabin, ele se fixaria num tipo: o do brasileiro gingado, com muitos macetes e nenhum caráter."4

Ocorrência 16: "Mas há um segundo dado, igualmente sórdido: a tentativa, em ambos os casos, de atacar a divulgação da foto, em vez de explicar o dinheiro."

Acreditamos que o uso em maior quantidade do definido, nesse caso, se deu em virtude de sua capacidade de conferir maior peso de argumentação na intenção locutiva, por meio da ênfase, da focalização que ele credita ao sintagma em que está inserido. Assim, o definido colabora decisivamente no processo de significação, porque constrói uma unicidade de referência, apagando as demais possibilidades.

Esse peso de argumentação a que nos referimos também diz respeito à evidência que o definido, precedendo o núcleo dos movimentos prospectivos, provoca enquanto um efeito de produção de verdade que se dá via um apagamento aparente do processo de construção do referente. Portanto, o definido, ao promover o efeito de que um objeto já é conhecido; é dado, corrobora para a construção de objetos-de-discurso como entidades absolutas, únicas. Isso implica dizer que o referente nesses casos deixa de ser "construído" pelos interlocutores para ser da ordem do já dado, do conhecido, pertencendo aos sentidos que circulam socialmente; haja vista o intuito de persuasão que

\footnotetext{
${ }^{4}$ Se bem que nessa ocorrência, o termo "um" da contração "num" pode ser compreendido como numeral, opondo-se, por exemplo, a "em dois tipos", o que a colocaria no rol das ocorrências de núcleo prospectivo precedido por determinante numeral.

${ }^{5}$ Em relação a essa ocorrência, uma explicação plausível para o núcleo de o movimento prospectivo ser precedido por determinante indefinido é o fato de se tratar de uma enumeração. No entanto, é fato que há ocorrências em que o núcleo do movimento prospectivo é precedido por determinante indefinido, conforme apregoa a Gramática Normativa.
} 
perpassa os textos opinativos e, por conseguinte, a necessidade enunciativa de construílos sob a égide da produção de uma verdade.

À guisa de demonstração, vejamos a ocorrência 13:

Ocorrência 13: "À frente das câmeras, contudo, surge a imagem mais constante de nosso cinema. Wilson Grey, único ator que apareceu em mais filmes do que ele, foi coadjuvante".

Aqui temos o artigo definido a determinando o sintagma imagem mais constante de nosso cinema. O núcleo desse movimento prospectivo é imagem e esse núcleo ainda não foi antes comentado no texto. De acordo com a gramática, ele deveria ser precedido por um artigo indefinido, uma vez que se configura como primeira aparição no texto. Dado que esse núcleo é precedido por um artigo definido, podemos supor que esse uso se dá em função de o produtor textual obter maior contundência em sua colocação ou ainda porque ele coloca essa imagem mais constante de nosso cinema como uma referência comum aos sentidos que circulam socialmente. Sob esse viés, é imprescindível considerar a ancoragem contextual envolvida na posição assumida pelo locutor e que se mostra de modo determinado por meio do artigo definido.

Ao contrário, se tivéssemos como precedente do núcleo desse movimento prospectivo (ocorrência 13) o artigo indefinido uma, a contundência da informação perderse-ia significativamente, pois o uso de uma imagem mais constante de nosso cinema impactaria como uma possibilidade dentre outras, o que provocaria a perda da unicidade na construção da referência.

O efeito de verdade que por ora ressaltamos diz respeito ao ato entendido como fato. Para isso, nos remontamos a que Perelman (1999) considera como ato e fato. Por ato, esse autor diz: Na relação ato-pessoa, entendemos por ato tudo o que pode ser considerado como emanação da pessoa; serão tanto ações como juízos, modos de expressão, reações emotivas, tiques involuntários (p. 228). E por fato ressalta que: O que é considerado um fato é independente da ação da pessoa (p. 241). Nesse sentido, podemos entender o ato como diretamente relacionado à pessoa, contrariamente ao fato. Por isso, ao afirmarmos que o efeito de verdade se dá a partir do ato entendido como fato, queremos dizer que o referente, construído nos movimentos prospectivos a partir do artigo definido enquanto determinante, passa do ato, que se caracteriza subjetivamente pela vivência do indivíduo e suas crenças, emoções, etc. para o fato, que se afasta da subjetividade para ser da ordem do social, do coletivo. Daí, a construção do referente ser vislumbrada como pertencente à ordem dos sentidos que circulam socialmente, posto que 
A partir do momento em que um ato exprime um fato, o valor que lhe é concedido é totalmente independente daquele da pessoa (PERELMAN, 1999, p. 240).

Com isso, os produtores dos textos opinativos ao utilizarem em maior número o artigo definido como determinante dos movimentos prospectivos concebem a sua escrita como verdade única, uma vez que optam pela construção dos objetos-de-discurso enquanto um fato, pois um fato é importante na argumentação porque se considera que ele forma o objeto de um acordo universal: ele deve ser admitido por todos (PERELMAN, 1999, p. 220).

Assim, o efeito de verdade bem como a ênfase postos nos sintagmas dos movimentos prospectivos são, sem dúvida alguma, resultados do uso de mecanismos pelo produtor textual em textos que demandam um posicionamento embasado num fato do mundo que está em voga durante o momento da produção. Destarte, nada melhor do que se utilizar de mecanismos que contribuem à argumentatividade num gênero em que cada recurso lingüístico torna-se essencial para viabilizar pontos de vista e, mais do que isso, para invocar do locutor a adesão necessária ao que defende, conforme postula Cunha (2002, p. 170;179):

O artigo de opinião expõe o ponto de vista de um jornalista ou de um colaborador do jornal (...). Comentando sempre algo que já foi dito, o artigo de opinião é uma gênero de enunciação subjetiva (...) é constituído de outros discursos sobre os fatos comentados e de antecipações das objeções do leitor, para fazer aderir ao seu ponto de vista e para criticar os outros com os quais mantém uma relação de conflito.

\section{Considerações finais}

Procuramos nesse estudo verificar qual a maior recorrência de determinantes que precedem o núcleo dos movimentos prospectivos e sua conseqüência para os textos opinativos que, predominantemente, são argumentativos. Chegamos à conclusão de que a maior recorrência desse determinante é realizada por meio do artigo definido. Isso constitui mais um recurso utilizado pelos produtores textuais no intento de não apenas elucidarem sua idéia sobre dado tema, mas por desejarem a instauração de um "pacto social" que permite a adesão do interlocutor ao posicionamento assumido por eles.

Sabendo do nosso objetivo de pesquisa, necessário se faz, a posteriori, pesquisar o porquê de muitas ocorrências não conterem determinantes precedentes ao núcleo dos movimentos prospectivos, como constatado por esse estudo. Aventamos, a partir dessa 
constatação, que tal fato parece ocorrer devido à emergência de especificadores que seguem os núcleos dos movimentos prospectivos. Parece-nos, ainda, que esses especificadores mantêm um funcionamento similar ao dos determinantes definidos. No entanto, essa hipótese ainda precisa ser trabalhada, o que faremos em outra ocasião.

\section{Referências bibliográficas}

BEAUGRANDE, R. de; DRESSLER, W. U. Introduction to text linguistics. London: Longman, 1981, p. 84-112.

BENVENISTE, E. Problemas de Lingüística Geral. Trad. Bras. São Paulo: Pontes, 1987, p.81-90.

CUNHA, D. A. C. O funcionamento dialógico em notícias e artigos de opinião. IN: DIONISIO, A. P.; MACHADO, A. R.; BEZERRA, M. A. (Org.). Gêneros Textuais \& Ensino. 2. ed. Rio de Janeiro: Lucerna, 2002.

CUNHA, C.; CINTRA, L. Nova gramática do português contemporâneo. 3.ed. Rio de Janeiro: Nova Fronteira, 2001, p.205-243.

DOLZ, J. \& SCHNEUWLY, B. Gêneros e progressão em expressão oral e escrita elementos para reflexões sobre uma experiência suíça (Francófona). In: DOLZ, J. \& SCHNEUWLY, B. Gêneros orais e escritos na escola. Tradução e organização: Roxane Rojo. Campinas, SP: Mercado de Letras, 2004.

FRANCIS, G. Rotulação do discurso: Um aspecto da coesão lexical de grupos nominais. In: CAVAlCANTE, M. M.; RODRIGUES, B. B.; CIULLA, A. (Org.). Referenciação. São Paulo: Contexto, 2003, p. 191-228.

MONDADA; L.; DUBOIS, D. (1995). Construção dos objetos de discurso e categorização: Uma abordagem dos processos de referenciação. IN: CAVALCANTE, M. M.; RODRIGUES, B. B.; CIULLA, A. (Org.). Referenciação. São Paulo: Contexto, 2003, p. 17-52. 
PERELMAN, C. Ato e pessoa na argumentação. In: Retóricas. Tradução de Maria Ermantina Galvão G. Pereira. São Paulo: Martins Fontes, 1999, p. 219-248.

SAUSSURE, F. de. Cours de Linguistique Générale. Paris: Payot, 1973.

\subsection{Corpus de referência}

CONY, C. H. Mais problemas do que votos. Folha de S. Paulo, São Paulo, 01 out. 2006. Objetivo nacional. Folha de São Paulo, São Paulo, 02 out. 2006. . Temporada de palpites. Folha de São Paulo, São Paulo, 03 out. 2006. . A turma dos exóticos. Folha de São Paulo, São Paulo, 04 out. 2006. . Tijolo de segurança. Folha de São Paulo, São Paulo, 05 out. 2006. . O homem da imprensa. Folha de São Paulo, São Paulo, 01 nov. 2006. . Sopa de entulho. Folha de São Paulo, São Paulo, 02 nov. 2006. . Tudo passa. Folha de São Paulo, São Paulo, 04 nov. 2006. . "Um filme é para sempre". Folha de São Paulo, São Paulo, 05 nov. 2006. . Um conselho ao papa. Folha de São Paulo, São Paulo, 06 nov. 2006. . Anatomia do vigarista. Folha de São Paulo, São Paulo, 02 dez. 2006. . Um gesto de paz. Folha de São Paulo, São Paulo, 03 dez. 2006. . Gastos e ganhos. Folha de São Paulo, São Paulo, 04 dez. 2006. . Jece Valadão. Folha de São Paulo, São Paulo, 05 dez. 2006. . Tempos modernos. Folha de São Paulo, São Paulo, 06 dez. 2006. ROSSI, C. Tiros na ética. Folha de São Paulo, São Paulo, 01 out. 2006. . O mito do mito. Folha de São Paulo, São Paulo, 03 out. 2006. . Candidatos de plástico. Folha de São Paulo, São Paulo, 04 out. 2006. . A origem dos "bandidos". Folha de São Paulo, São Paulo, 05 out. 2006. A rota que está ausente. Folha de São Paulo, São Paulo, 06 out. 2006. Lula e as "gripes". Folha de São Paulo, São Paulo, 01 nov. 2006. . O grito e o pacto. Folha de São Paulo, São Paulo, 02 nov. 2006. . Cenas patéticas. Folha de São Paulo, São Paulo, 03 nov. 2006. . O Carandiru aéreo. Folha de São Paulo, São Paulo, 04 nov. 2006.

. O espelho e a indigência mental. Folha de São Paulo, São Paulo, 05 nov. 2006. De filósofos e de profissionais. Folha de São Paulo, São Paulo, 07 dez. 2006. 
Sobre Pinochet e a Plaza Itália. Folha de São Paulo, São Paulo, 12 dez. 2006.

. Um Nobel para Lula. Folha de São Paulo, São Paulo, 13 dez. 2006. . Falta a sua pressão. Folha de São Paulo, São Paulo, 14 dez. 2006. . Resta o escracho. Folha de São Paulo, São Paulo, 20 dez. 2006. 